\title{
Un nuevo tipo penal de femicidio en un nuevo Código Penal para Chile*
}

\author{
Emanuele Corn**
}

\begin{abstract}
RESUMEN
El objetivo de la presente contribución consiste en ofrecer una propuesta clara y argumentada para una nueva formulación del tipo penal de femicidio. En la primera parte se constatará la importancia de tener un tipo específico en el ordenamiento nacional resumiendo, a continuación, los principales defectos de la norma introducida por la Ley 20.480 de 2010 ya evidenciados por la doctrina. En la segunda parte se buscarán y analizarán las bases para el cambio mirando tanto la experiencia comparada como el Anteproyecto de Código Penal de 2005 y el Proyecto de 2014. En la tercera parte, en fin, se enseñará el texto de la propuesta, fundamentando los términos elegidos y tratando de responder a hipotéticas críticas.
\end{abstract}

Femicidio - delitos contra las personas - igualdad (principio de)

\section{A new offence of femicide in a new chilean penal code}

\begin{abstract}
The goal of this paper is to make a clear proposal for a new formulation of the femicide's offence in Chile. In the first part, it will be clarified the importance to have a specific rule in the law in force in the country and it will be summarized the most important deficiencies of the Ley 20.480 of 2010, that introduced the new offence. In the second part, there will be investigated the bases for the change, looking at comparative law and at the drafts of 2005 and 2014 for a new penal code. In the third part, it will be offered the text of the proposal with an explanation of the taken decisions and the answers to bypothetical critiques.
\end{abstract}

Femicide - offence against the person - equality (principle of)

* Dedico este trabajo a mi querido amigo José Luis Guzmán Dalbora.

** Doctor en Derecho Penal por la Universidad de Trento (Italia) y Salamanca (España). Investigador Asociado adscrito a la Facultad de Ciencias Jurídicas y Sociales de la Universidad Autónoma de Chile. Docente contratado en la Universidad de Trento (Italia). Correo electrónico: emanuele.corn@unitn.it

Artículo recibido el 3 de julio de 2014 y aceptado para su publicación el 27 de marzo de 2015. 


\section{UNA PROPUESTA DE REFORMA, ¿PARA QUÉ?}

\section{La importancia de la introducción de un tipo de femicidio en Chile}

En Chile, desde hace varios años, se tramitan proyectos de ley con el fin de atacar de forma cada vez más profunda y eficaz la plaga social de la violencia contra las mujeres y la violencia intrafamiliar. El presente trabajo centra su atención en una de las propuestas más controvertidas: la creación de un tipo penal especial para la sanción de femicidio.

El proyecto de ley, presentado en abril de 2007 y aprobado definitivamente a fines de 2010, junto con otras importantes medidas, quiso modificar el Código Penal chileno importando el novedoso tipo penal desde Costa Rica, primer país en el mundo que introdujo, el 30 de mayo de 2007, una disposición ad hoc para el femicidio ${ }^{1}$.

El nuevo apartado segundo del artículo $390 \mathrm{CP}^{2}$ reproduce fielmente el modelo costarricense, creando un tipo penal que simplemente llama con un nombre diferente ciertos ejemplos de parricidio que antes de la reforma ya se castigaban y con la misma pena.

Las diferencias entre las normas de los dos países estriban, por un lado, en la ubicación de una y otra norma: mientras la chilena la situó en el Código Penal, el legislador costarricense prefirió incluirla en una ley especial; y, por otro, en la ampliación, por parte de la norma chilena, del catálogo de los posibles sujetos pasivos, pues la víctima puede ser no solo la cónyuge o conviviente, sino también la persona que anteriormente lo haya sido.

La inserción de esta figura en el Código Penal tuvo el indudable mérito de fortalecer el debate y la atención de toda la sociedad respecto de la violencia contra la mujer ${ }^{3}$.

Además, no se puede desconocer que por medio de la reforma es posible acceder a datos más acertados para contabilizar el fenómeno, ya que las cifras son un ingrediente indispensable para predisponer políticas públicas que puedan definirse serias y racionales ${ }^{4}$.

\footnotetext{
${ }^{1}$ Se trata de la ley de penalización de la violencia contra las mujeres, cuyo artículo 21 reza: Femicidio: Se le impondrá pena de prisión de veinte a treinta y cinco años a quien dé muerte a una mujer con la que mantenga una relación de matrimonio, en unión de hecho declarada o no (Art. 21 Ley 8.589 de 2007).

Toda la legislación de este país está disponible en el buscador del Sistema Costarricense de Información Jurídica: http://www.pgr.go.cr/Scij/

${ }^{2}$ A pesar de ser de conocimiento común, se ofrece en pie de página el texto vigente del artículo 390 CP para facilitar su consulta, cuando se propondrá su análisis, y el cotejo con normas extranjeras y propuestas de reforma.

1. El que, conociendo las relaciones que los ligan, mate a su padre, madre o bijo, a cualquier otro de sus ascendientes o descendientes o a quien es o ha sido su cónyuge o su conviviente, será castigado, como parricida, con la pena de presidio mayor en su grado máximo a presidio perpetuo calificado.

2. Si la víctima del delito descrito en el inciso precedente es o ha sido la cónyuge o la conviviente de su autor, el delito tendrá el nombre de femicidio.

${ }^{3}$ Esto en Chile, como en otros países que optaron por "sexualizar la respuesta punitiva frente a la violencia de género" creando tipos especiales sin alterar la penalización, como ocurrió en Suecia según lo que indica Toledo Vásquez, P., “¿Tipificar el femicidio?”, en Anuario Der. Humanos U.Ch., 4, 2008, pp. 215-216.

${ }^{4}$ Se simplifica la generación de información estadística desagregada, junto con facilitarse el seguimiento de la acción del aparato de justicia y de la jurisprudencia (interesante al respecto la sección acerca de "parricidio y femicidio" en la revista Doctrina y Jurisprudencia penal ( $\left.\mathrm{N}^{\circ} 11-2012\right)$, pp. 109-124).
} 
Todos estos elementos han favorecido y estimulado la realización de investigaciones especializadas de los casos de violencia contra las mujeres, "entendiéndola como actividad que implica reunir elementos de prueba que permitan establecer no solo la ocurrencia de los hechos y la participación del imputado en ellos, sino que además tender a establecer el contexto relacional en el que estos ocurren" ${ }^{5}$. Las mejoras en esta difícil empresa producen resultados concretos, como el mejor tratamiento procesal del acontecimiento psicológico de la retractación de la víctima (en los casos en que afortunadamente el resultado de muerte no se produce), sin que sea necesario acudir a modificaciones legales como, por ejemplo, la introducción de la prohibición de retractación que pueden producir severas externalidades negativas ${ }^{6}$.

Tampoco hay que olvidar que la Ley 20.480 de 2010 también modificó el artículo $10 \mathrm{CP}$ introduciendo, por fin, el estado de necesidad general ${ }^{7}$. En efecto, el Parlamento discutía acerca de la exigibilidad de otra conducta respecto de la reacción homicida de las mujeres maltratadas y solo la útil participación en la discusión de Enrique Cury permitió que la circunstancia adquiriera el alcance general contenido en el texto finalmente aprobado. En todo caso, el nuevo numeral 11 del artículo $10 \mathrm{CP}^{8}$ contempla ahora una eximente potencialmente eficaz para los casos más extremos de amenazas y agresiones a la mujer por su actual o expareja y nos da muestra de la capacidad que tuvo la ley para captar varios de los posibles resultados de una agresión: no solo cuando la mujer tristemente sucumbe, sino también cuando logra salvarse a costa de terminar con la vida de su agresor. Realmente son dos lados de la misma moneda que siempre hay que tener presente a la hora de analizar el problema. Este artículo, por cuestiones de espacio, puede mirar tan solo al primero. Con todo, no puede obviarse que sin una debida consideración del segundo aspecto 9 toda propuesta de modificación del femicidio resultaría incompleta.

${ }^{5}$ Car Silva, M., "Comentario a la sentencia definitiva condenatoria dictada por el sexto tribunal oral en lo penal de Santiago por el delito de femicidio frustrado y otros”, en Revista jurídica del ministerio público, LV, junio, 2013, p. 179.

${ }^{6}$ Son de rechazar por completo las consideraciones de Garita (Garita Vilchez, A.I., La regulación del delito de Femicidio/Feminicidio en América Latina y el Caribe, Campaña del Secretario General ÚNETE para poner fin a la violencia contra las mujeres, Ciudad de Panamá, 2013, p. 45) que llega a afirmar: "[...] en algunos casos principios como el del impulso procesal de oficio, publicidad o los criterios de la libre valoración de la prueba se convierten en serios obstáculos procesales que impiden a las mujeres su derecho a la justicia y terminan siendo mecanismos generadores de impunidad".

${ }^{7}$ Santibáñez Torres, M.E., Vargas Pinto, T., "Reflexiones en torno a las modificaciones para sancionar el femicidio y otras reformas relacionadas (Ley 20.480)", en Revista chilena de Derecho, XXXVIII, 1, 2011, pp. 196197. También: Hernández Basualto, H., "Artículo 10”, en Mera Figueroa, J., Couso, J., Hernández Basualto, H., y otros (dir.), Código penal comentado - Parte general, Legal Publishing, Santiago, 2011, pp. 269 y ss. y 274 y ss.

${ }^{8}$ Las citadas Santibáñez Torres, M.E., Vargas Pinto, T., "Reflexiones en torno a las modificaciones para sancionar el femicidio...", p. 196, con perspicacia, recuerdan que el Código tuvo, hasta 1953, un numeral 11 que también tocaba cuestiones relacionadas al género. En efecto, se trataba de la vieja eximente de responsabilidad para el marido que mataba o hería a su mujer y a su "cómplice" al sorprenderla in fragranti en "delito de adulterio". Casi sesenta años más tarde el curso de la historia pasa por un camino similar, pero en dirección contraria.

${ }^{9}$ De esto, con un análisis profundizado que prescinde de la reforma realizada por la Ley 20.480 de 2010 , se ocupa: Villegas Díaz, M., "Homicidio de la pareja en violencia intrafamiliar. Mujeres homicidas y exención 
Estos elementos parecen suficientes para decir que se equivocaba quien, antes de la aprobación de la Ley 20.480, afirmaba que, al castigarse el parricidio con las penas más altas del ordenamiento, el problema del femicidio, desde el punto de vista normativo, no existía y su introducción en Chile no era necesaria ${ }^{10}$.

\section{Los defectos técnico-dogmáticos y los límites político-criminales de la nueva norma}

A estos indudables méritos, centrados sobre todo en la oportunidad de introducir el nuevo delito en el ordenamiento penal, se suman, sin embargo, una gran cantidad de críticas respecto de cómo el legislador realizó la tipificación de la conducta de femicidio. En el presente artículo -sumándome a los que consideran que el legislador hubiese podido aprobar una norma más incisiva y contundente-, después de presentar en seguida las principales críticas al tipo vigente ya expresadas por la doctrina, expondré una propuesta de formulación alternativa del tipo.

En extrema síntesis ${ }^{11}$, una primera crítica se refiere a la decisión de introducir en el Código un tipo de femicidio muy distinto de lo que los estudios sociológicos y la misma opinión pública consideran como tal ${ }^{12}$. Esto dificulta la recopilación de datos relativos a los procedimientos penales que midan realmente el fenómeno y que, en general, se puedan considerar completos, consolidados y útiles ${ }^{13}$.

de la responsabilidad penal", en Revista de Derecho, Universidad Austral de Chile, XXXIII, 2, 2010, pp. 149 ss. También: Tapia Ballesteros, P., "Legítima defensa. Requisitos y aplicabilidad en supuestos de violencia de género", en Doctrina y Jurisprudencia Penal, 16, 2014, pp. 37-60. A mi juicio, el nuevo numeral 11 del artículo 10 CP, aunque mejorable, se mueve en la justa dirección. El Código, desde hace mucho tiempo, precisaba de una norma de esta naturaleza no solo para resolver los problemas conectados con la violencia de género. Por su parte, Cury fue capaz de aprovechar la ocasión ofrecida en la discusión parlamentaria dedicada a la violencia contra las mujeres para sugerir un cambio que va mucho más allá del alcance originalmente previsto. La conexión con este tema particular genera las dificultades más grandes en la interpretación, porque no se dio a Cury la posibilidad de completar su diseño, resolviendo los problemas de sobreposición con otras normas. En particular, comentando el resultado de la reforma de la Ley 20.480, él afirmaba que de la introducción del numeral 11 habría debido deducirse una derogación tácita del numeral 7; Cury Urzúa, E., "El estado de necesidad en el Código Penal chileno", en AA.VV., La ciencia penal en la Universidad de Chile, Facultad de Derecho Universidad de Chile, Santiago, 2013, p. 255.

${ }^{10}$ Apreciaciones en este sentido, en opinión de Jorge Mera, no solo parecen equivocadas, sino que "trasuntan una aproximación muy superficial al problema", Mera Figueroa, J., "Femicidio", en Red chilena contra violencia doméstica y sexual (Dir.) Tipificación del femicidio en Chile: un debate abierto, disponible en: <http://www.boelllatinoamerica.org/downloads/Tipificar_el_femicidio_un_debate_abierto.pdf>, Santiago de Chile, 2009, p. 54.

${ }^{11}$ Una exposición más detallada de defectos técnico-dogmáticos y límites político-criminales se ofrece en Corn, E., "La revolución tímida. El tipo de femicidio introducido en Chile por la Ley 20.480 en la perspectiva del Derecho comparado", en Revista de Derecho, Universidad Católica del Norte, vol. 21, n. 2,. 2014, de próxima publicación, pp. 23-29.

${ }^{12}$ Acerca de lo que se entiende en sociología por femicidio y feminicidio desde las orígenes del concepto a las legislaciones vigentes en varios países: Laurenzo Copello, P., "Apuntes sobre el feminicidio", en Revista de Derecho penal y criminología-UNED, 8, 2012, pp. 119-126 y Garita Vilchez, A.I., La regulación del delito de Femicidio /Feminicidio en América Latina y el Caribe, pp. 15-18.

13 Obsérvese que, cumplidos tres años de la reforma del artículo $390 \mathrm{CP}$, ni siquiera el Sernam utiliza el nuevo tipo penal para calcular la dimensión del fenómeno (http://portal.sernam.cl/?m=programa\&i=8) y lo mismo ocurre con la Fiscalía (si se mira a los artículos publicados en la revista jurídica del ministerio público, 
Pasando a un análisis enfocado en defectos de ubicación dogmática y redacción técnico-legislativa de la nueva norma, es factible señalar, de entrada, cómo la inserción del femicidio en el cuerpo del artículo 390 CP determina una dependencia de este con el parricidio, en el sentido que no todo homicidio en el que la víctima sea mujer se puede denominar así, sino tan solo aquellos en que la víctima fue en algún momento cónyuge o conviviente del autor. El campo semántico de la palabra se restringe enormemente, hasta el punto, por ejemplo, de que no es femicidio dar muerte a la "polola" no conviviente $^{14}$ o a la compañera de trabajo que no quiere establecer una relación de pareja. Estas conductas no solo siguen llamándose homicidios simples, sino que su respuesta sancionatoria es (mucho) más blanda ${ }^{15}$.

Sin modificar en sustancia los equilibrios de la legislación anteriormente vigente, la fórmula del segundo inciso del artículo 390 CP mantuvo intactas las garantías constitucionales de igualdad formal entre hombres y mujeres ante la ley ${ }^{16}$, pero a costa de mantener el fulcro real de protección en la familia y no en la mujer, como habría de esperarse de una novedad legislativa como esta.

En efecto, el tipo del inciso segundo del artículo 390 CP sanciona situaciones de femicidios que se suelen denominar "íntimas"17, es decir, que corresponden a un delito cometido en el ámbito de una familia o "ex-familia”. La conexión entre el femicidio y el parricidio impone al primero compartir la historia del segundo, que desde la antigüedad ha justificado su existencia -y la consiguiente agravación de la pena- por la infracción de la obligación de protección que el Derecho impone a los parientes más estrechos ${ }^{18}$. El femicidio chileno de la Ley 20.480 de 2010 no mueve una coma el statu quo al respecto ${ }^{19}$.

en orden cronológico, el último es Rodríguez Manríquez, R., "Informe sobre femicidio en Chile. Estadísticas relevantes 2012 y datos comparativos", en Revista jurídica del ministerio público, LIII, diciembre, 2012, p. 165.

${ }^{14}$ Lamentablemente, el estudio de Castañeda Meneses et al. da cuenta todavía de cierta persistencia entre los adolescentes de prácticas y actitudes "tradicionales" que sugieren la posición social subordinada de las mujeres respecto de los hombres; Castañeda Meneses, P., Urquieta Álvarez, M.A., Donoso Pinochet, M., Estudio exploratorio sobre relaciones de pareja en adolescentes desde la perspectiva de la violencia basada en el género, Universidad de Valparaíso-Seremi Región de Valparaíso, Valparaíso, 2012, p. 37.

${ }^{15}$ Nótese, al revés, que no solo sigue llamándose parricidio la conducta homicida de un hombre que mate a su madre, sino que, también, se ocupa la misma palabra para el padre que mata a su hija. Sobre la base de estos y otros equívocos, Jorge Mera considera que se justificaría una figura autónoma para el femicidio; Mera Figueroa, J., "Femicidio", pp. 54-55.

${ }^{16}$ Toledo Vásquez, P., "Leyes sobre femicidio y violencia contra las mujeres. Análisis comparado y problemáticas pendientes”, en Red chilena contra violencia doméstica y sexual (Dir.) Tipificación del femicidio en Chile: un debate abierto, disponible en: <http://www.boell-latinoamerica.org/downloads/Tipificar_el_femicidio_un_debate_abierto. pdf, Santiago de Chile, 2009, p. 45.

${ }^{17}$ La diferenciación entre femicidio "íntimo" y "no íntimo” es una de las más frecuentes en la literatura sobre el tema; véase Laurenzo Copello, P., “Apuntes sobre el feminicidio”, pp. 123-125.

18 Mera Figueroa, J., "Femicidio”, p. 54 y Van Weezel de la Cruz, A., "Lesiones y violencia intrafamiliar”, en Revista chilena de Derecho, XXXV, 2, 2008, pp. 223-225.

19 Véase Corcoy Bidasolo, M., "Problemática jurídico-penal y político -criminal de la regulación de la violencia de género y doméstica”, en Revista de Derecho, Universidad Católica de Valparaíso, XXXIV, 1, 2010, pp. 327-329. Se trata también de una de las tesis afirmadas por Ried S., N., "Un delito propio. Análisis de los fundamentos de la ley de femicidio", en Revista de Estudios de la Justicia, 16, 2012, p. 172. 
En realidad, el hecho que se castigue a los ex refuerza el concepto, porque subraya cómo el vínculo familiar se mantiene en el tiempo, tanto a nivel social como para el Derecho penal, no obstante la configuración de la causal de término establecida por el Derecho civil; y es bien criticable que no se ponga un punto final a esto ${ }^{20}$.

No se puede afirmar, además, que el legislador no sepa aprobar normas que realmente protejan a las mujeres "por el hecho de ser mujeres" 21 , pues ya lo ha hecho en otras partes del Código.

El primer ejemplo significativo es la circunstancia sexta del artículo $12 \mathrm{CP}$ que incluye en el catálogo de las agravantes genéricas el "abusar el delincuente de la superioridad de su sexo o de sus fuerzas, en términos que el ofendido no pudiera defenderse con probabilidades de repeler la ofensa" ${ }^{22}$. Sin embargo, al respecto hay que recordar que, desde las primeras interpretaciones de Fuensalida ${ }^{23}$, no se cuestionan las razones que niegan ipso iure su aplicación en casos de violación, estupro y abusos sexuales en general $^{24}$, lo que hoy debiera reconsiderarse, porque, también en virtud de las anteriores reformas de estos tipos penales, hay que excluir el hecho que la circunstancia se configure de forma automática en todos los casos que lamentablemente se dan en la práctica ${ }^{25}$.

${ }^{20}$ También critican la opción tomada: Santibáñez Torres, M.E., Vargas Pinto, T., "Reflexiones en torno a las modificaciones para sancionar el femicidio...”, p. 205.

Del mismo modo, es poco relevante la inclusión de los convivientes entre los potenciales sujetos activos y pasivos, aunque esto amplíe enormemente el ámbito de aplicación de la ley (cfr. Van Weezel de la Cruz, A., "Lesiones y violencia intrafamiliar", p. 224) y amplifique ciertos problemas de interpretación de la norma de parricidio (indicados por: Ossandón Widow, M.M., "La faz subjetiva del tipo de parricidio", en Revista de Derecho, Universidad Católica de Valparaíso, XXXIV, 1, 2010, p. 415). En efecto, así se reajusta parcialmente el concepto jurídico penal de familia a la realidad social contemporánea de Chile, pues en muchísimos ámbitos estamos lejos de la equiparación entre cónyuge y conviviente (cfr. Scheechler Corona, C., "El cónyuge y el conviviente en el Código Penal chileno: perspectivas de un tratamiento (dispar) desde la ley de violencia intrafamiliar", en Doctrina y Jurisprudencia Penal, 11, 2012, p. 43).

${ }^{21}$ Esta es la fórmula introducida en el debate sociológico como definición de femicide por la antropóloga Diana Russell a partir de sus conferencias en las décadas de los setenta del siglo pasado; cfr. Russell, E.H., D., Caputi, J., "Femicide: Sexist terrorism against women", en Radford, J., Russell E.H., D., (ed.), Femicide: The Politics of Woman Killing, Nueva York, NY, 1992, pp. 13-24.

22 Intuyen el elemento sin tener espacio para fundamentar la opinión manifestada: Santibáñez Torres, M.E., Vargas Pinto, T., "Reflexiones en torno a las modificaciones para sancionar el femicidio...”, p. 205. Véase también: Mera Figueroa, J., “Artículo 12 ( $6^{\mathrm{a}}$ y $\left.18^{\mathrm{a}}\right)$ ”, en Mera Figueroa, J., Couso, J., Hernández Basualto, H., y otros (dir.), Código penal comentado - Parte general, Legal Publishing, Santiago, 2011, pp. 329-331 y 353-357.

${ }^{23}$ Fuensalida, A., Concordancias y Comentarios - Código Penal Chileno, Imprenta Comercial, Lima, 1883, pp. 96, 102 y 107.

${ }^{24}$ Cfr. Rodríguez Collao, L., Delitos sexuales, reimpresión de la primera edición con anexo de actualización, Editorial Jurídica, Santiago, 2012, p. 285; como ejemplo jurisprudencial se indica: SCS de 17.01.2001, en causa Rol No 2146-2000.

${ }^{25}$ Sería interesante también la circunstancia agravante decimoctava-ejecutar el hecho con ofensa o desprecio del respeto que por la dignidad, autoridad, edad o sexo mereciere el ofendido [ ] cuando él no haya provocado el suceso-. Sin embargo, su interés ahora parece encerrado en la discusión teórica, porque por la evolución del tiempo ha caído en desuso y en descrédito; en este sentido: Ramírez Guzmán, M.C., "Anteproyecto de Código Penal: hacia una racionalización de las circunstancias modificatorias de responsabilidad penal. El caso de las agravantes", en Política criminal, 4, A2, 2007, p. 4. 
En todo caso, tampoco esta agravante es el único elemento dirigido a sancionar mayormente las conductas perpetradas contra las mujeres, porque la circunstancia de discriminación (la 21ª del Art. 12) recién incorporada al Código Penal (Ley 20.609 de 2012) prevé también, entre los factores que pueden modificar la pena, el sexo de la víctima ${ }^{26}$.

El listado de las deficiencias del nuevo tipo chileno de femicidio se cierra indicando un límite político-criminal que puede general problemas sistemáticos ${ }^{27}$.

Al existir tipos penales especiales sexualizados, las mujeres se convierten en víctimas por definición, con un refuerzo del lugar de víctimas que, desde una perspectiva feminista, "acaba por reducir, en el imaginario social, el empoderamiento de las mujeres" 28. Además, adoptando este modelo se asume el riesgo de discriminar en los tipos penales respecto de otras formas de violencia cuyas víctimas no son mujeres ${ }^{29}$, como son, por ejemplo, las personas con una identidad de género diferente. La ausencia en Chile de una legislación en materia de parejas formadas por personas del mismo sexo obstaculiza una interpretación uniforme de cuestiones como, por ejemplo, el posible castigo por femicidio de una mujer lesbiana que mata a su pareja conviviente o ex-conviviente ${ }^{30}$.

En mi opinión, el dato literal del nuevo apartado segundo del artículo 390 CP permite el castigo del femicidio entre lesbianas, mientras excluye la sanción, a título de femicidio, en el caso de un varón que muere a manos de su pareja homosexual actual o ex-conviviente. La víctima tiene que ser de sexo femenino mientras que el autor puede ser tanto hombre como mujer, porque en todas aquellas partes en que el Código emplea la voz "autor", incluso en contextos de violencia sexual, se refiere, indistintamente, a ambos géneros. De no haber querido este resultado, el legislador habría tenido que explicitarlo y dar una justificación adecuada a la evidente discriminación que ello hubiese supuesto.

A este respecto, la propuesta contenida en la parte III de este trabajo se basa en una tutela de la identidad de género y no del sexo como hace ahora el artículo $390 \mathrm{CP}$. En efecto, el fenómeno por combatir no es la violencia entre los sexos sino la violencia

${ }^{26}$ A poco menos de dos años de vigencia de la ley, ya se va formando literatura (no solo dedicada al tema específico que más interesó a la opinión pública en la fase final del debate antes de su aprobación, es decir, la orientación sexual): cfr. Corn, E., "Apuntes acerca del problema de la discriminación y de su tratamiento penal”, en Revista chilena de derecho y ciencias penales, vol. 2, n. 3, 2013, pp. 139-156; Hernández Basualto, H., "Discriminación y Derecho Penal", en Revista chilena de derecho y ciencias penales, vol. 2, n. 3, 2013, pp. 157-175; Salinero Echeverría, S., "La nueva agravante penal de discriminación. Los "delitos de odio", Revista de Derecho, Universidad Católica de Valparaíso, XLI, 2, 2013, p. 301.

${ }^{27}$ Véase Toledo Vásquez, P., "Leyes sobre femicidio y violencia contra las mujeres”, pp. 45-46.

${ }^{28}$ Toledo Vásquez, P., "Leyes sobre femicidio y violencia contra las mujeres”, p. 46. En el mismo sentido: Larrauri (2007).

29 Valen acá las consideraciones respecto de la legislación antidiscriminatoria de Argentina de Zaffaroni, E.R., "Observaciones sobre la delincuencia por odio en el Derecho Penal argentino", en García Valdés, C., et alii (Eds.), Estudios Penales en homenaje a Enrique Gimbernat, Tomo II, Edisofer, Madrid, 2008, pp. 1747-1748.

${ }^{30}$ Entre las varias citas posibles, a favor del castigo por femicidio: Santibáñez Torres, M.E., Vargas Pinto, T., "Reflexiones en torno a las modificaciones para sancionar el femicidio...", p. 205; en contra, Taladriz Eguiluz, M.J., Rodríguez Manríquez, R., "El delito de femicidio en Chile”, en Revista jurídica del ministerio público, XLVI, marzo, 2011, p. 220. 
de género que se basa en relaciones desiguales de poder entre individuos y que no se generan -stricto sensu- por el dato biológico de poseer cierto órgano sexual en lugar de otro, sino de la íntima e individual construcción de cierta identidad de género por parte de las personas ${ }^{31}$.

\section{Modificar y no derogar}

Tantos defectos y cuestionamientos podrían llevar el intérprete a pensar acerca de la oportunidad de derogar la nueva norma, volviendo a la situación anterior, lo que no significaría -es evidente- descriminalizar la conducta asesina, sino simplemente volver a llamar parricidio lo que ahora en Chile el Código denomina femicidio.

Sin embargo, como escribe Buompadre respecto de la situación argentina, el problema ya no reside "en determinar si la respuesta penal es o no la herramienta más adecuada” para enfrentar el problema de la violencia de género -interrogante que el Parlamento contestó afirmativamente-, "sino si las figuras introducidas al texto punitivo se corresponden o no con la verdadera estructura ontológica del femicidio en sentido estricto" 32 .

A pesar de esta firme y manifiesta voluntad de incorporar en el ordenamiento penal un delito específico de femicidio, propia de muchos Parlamentos latinoamericanos, en un artículo de doctrina, como este, cabría igualmente espacio para disentir. Sin embargo, mi opinión va en el sentido que es necesario superar las deficiencias de la nueva norma, porque un tipo de femicidio como delito autónomo respecto del homicidio es un instrumento importante, aunque no el único, para una correcta sanción de la violencia contra las mujeres. Su introducción en el ordenamiento chileno fue una decisión correcta, mientras que su puesta en práctica se colocó muy por debajo de las necesidades sociales.

Por lo tanto, considero positivo que el Proyecto de ley que establece un nuevo Código Penal presentado en el Parlamento ${ }^{33}$ en el verano de 2014 (en adelante, Proyecto 2014) prevea un tipo de femicidio (Art. 213). Este proyecto, fruto de una comisión de académicos $^{34}$, en varios puntos propone elecciones dogmáticas y político-criminales

${ }^{31}$ Da muestra del desequilibrio presente en la tutela de personas con orientación sexual diferente el fallo del TOP de Puerto Aysén de marzo 2014 (inédito) en el que el fiscal atribuía a la victimaria M. Magdalena Carvajal el delito de femicidio frustrado.

32 "[...] ahora solo falta analizar el texto definitivo de la reforma y someterlo al análisis crítico"; Buompadre, J.E., "Los delitos de género en la reforma penal (Ley $\mathrm{N}^{\circ}$ 26.791)", en Revista pensamiento penal, $\mathrm{N}^{\circ} 152$, disponible en: <www.pensamientopenal.com.ar>, 2013, p. 12. Evidentemente siempre cabe espacio -añado yo- para una propuesta de modificación.

33 Boletín $\mathrm{N}^{\circ}$ 9.274-07.

${ }^{34}$ La comisión redactora fue convocada a instancias del Ministerio de Justicia e integrada, de manera permanente, por los profesores de Derecho penal Juan Domingo Acosta Sánchez, Antonio Bascuñán Rodríguez, Jorge Bofill Genzsch, Juan Pablo Cox Leixelard, Héctor Hernández Basualto, Francisco Maldonado Fuentes y Álex van Weezel de la Cruz, bajo la presidencia del Subsecretario de Justicia y la secretería técnica del departamento de asesoría y estudios del mismo ministerio. La comisión celebró 90 sesiones de trabajo a lo largo de todo 2013. 
valientes e impopulares, entre las que perfectamente podría haberse sumado la exclusión -dentro del catálogo de las infracciones más graves- de un tipo específico de femicidio. Sin embargo, la comisión (que hasta el momento no ha publicado los verbales de sus sesiones de trabajo) finalmente optó por su conservación.

Por su parte, las instituciones internacionales siguen enviando a Chile, como a los demás países de Latinoamérica, mensajes ${ }^{35}$ e instrucciones para que implementen y perfeccionen sus políticas, también penales, para combatir la violencia contra las mujeres. Entre estas, el Comité CEDAW ${ }^{36}$ muestra su preocupación en torno a la Ley 20.480 de 2010, por cuanto "restringe el femicidio al entorno familiar y la violencia sexual, dejando fuera otros ámbitos de violencia y cuestiona la eficacia de las medidas adoptadas para impedirlo" 37 . El mismo Comité "insta" a Chile "a que estudie todos los casos de feminicidio a fin de mejorar la efectividad de las medidas de protección de las mujeres víctimas de la violencia doméstica" 38 .

En fin, la necesidad de modificar el tipo penal también surge a partir de las primeras complicaciones con las que se ha enfrentado la jurisprudencia al momento de interpretarlo 39 .

35 Ana Isabel Garita Vilchez (actualmente Ministro de Justicia de la República de Costa Rica), en el marco de la Consultoría de la Campaña del Secretario General de las Naciones Unidas, ÚNETE, para poner fin a la violencia contra las mujeres, afirma que la discusión respecto de la aprobación de la legislación especial dirigida a la incorporación del delito de femicidio/feminicidio a la normativa penal nacional de muchos países latinoamericanos se genera porque "aunque la muerte de las mujeres está formalmente contenida en los Códigos penales, su configuración típica no se ajusta a los bienes jurídicos afectados ni al daño que genera esta conducta, ni a las condiciones de subalternidad de las mujeres víctimas”; Garita Vilchez, A.I., La regulación del delito de Femicidio /Feminicidio en América Latina y el Caribe, pp. 44-45. La autora espera "que la legislación sustantiva y procesal aprobada, así como la institucionalidad especializada para investigar, perseguir y juzgar el asesinato de mujeres no solo elimine la impunidad de estos hechos, sino que incida en su contención y prevención, consolidándose en la región una cultura de los operadores de justicia fundamentada en principios de igualdad real, no discriminación, probidad y transparencia en la función publica, así como de eficacia del sistema de justicia en el logro de su fin principal: la paz social". Para los que entienden el Derecho penal rígidamente enmarcado en los estrechos límites impuestos por una visión meramente retributiva de la pena, estas palabras no pueden no resultar indigestas. Sin embargo, es imposible no tomarlas en la debida cuenta, no solo -obviamente- por el respeto que merece la ONU, sino porque hay que reconocer que son el fruto de un movimiento político importante y responden a demandas sociales legítimas a las que los penalistas tienen que ofrecer respuesta.

36 La Convención ONU sobre la Eliminación de todas las Formas de Discriminación contra la Mujer (CEDAW), adoptada el 8 de diciembre de 1979, es el principal instrumento jurídico internacional relativo a los derechos de las mujeres. El artículo 17 de la Convención instituye un Comité compuesto por personas expertas en la materia procedentes de 23 países como mecanismo para velar por su aplicación.

37 Valdés Echenique, T., "La CEDAW y el Estado de Chile: viejas y nuevas deudas con la igualdad de género”, en Anuario Der. Humanos U.Ch., 9, 2013, p. 176; cfr: Comité CEDAW, Observaciones finales sobre los informes periódicos quinto y sexto de Chile, adoptadas por el Comité en su $53^{\circ}$ período de sesiones $\left(1^{\circ}\right.$ a 19 de octubre de 2012) (CEDAW/C/CHL/CO/5-6). Disponible en: < http://acnudh.org/wp-content/uploads/2013/01/CEDAWChile-2012-ESP.pdf>, 2012, párrafo 20.

${ }^{38}$ Comité CEDAW, Observaciones finales , párrafo 21 c).

${ }^{39}$ Ejemplos de interpretaciones contradictorias de la Ley 20.480 por parte de la jurisprudencia son: STOP de Valdivia de 28.05.2012, en causa RUC: 1000281567-8; STOP de Chillán de 16.04.2012, en causa RUC: 1100250776-7; STOP de Los Ángeles de 05.03.2012, en causa RUC: 0900948786-4; todas citadas en: Doctrina y Jurisprudencia penal ( $\mathrm{n}^{\circ} 11$ - 2012), pp. 109-118. 
Al respecto merece especial atención el fallo del TOP de Villarrica de 2011 que tomó postura respecto de la agravante de superioridad de fuerza y de sexo (No 6, Art. 12 $\mathrm{CP}$, ya nombrado más arriba) al considerarla integrada en el tipo penal de femicidio y, por tanto, no aplicable en el caso concreto. La afirmación es evidentemente falaz y prueba de esto se da considerando que, si no hubiese habido introducción de la nueva denominación y la conducta realizada hubiese seguido indicándose con el antiguo nombre de parricidio, los magistrados sí habrían calculado la agravante ${ }^{40}$ al considerar que el victimario medía 20 centímetros y pesaba 20 kilos más que la víctima. En tantos años de vigencia nadie había cuestionado la aplicabilidad de la circunstancia sexta a los casos de homicidio o parricidio y el hecho que ahora, tras la introducción del femicidio, se genere una confusión cuyo efecto sea la rebaja de la pena, demuestra que una mejor definición del tipo es necesaria.

\section{MODIFICAR: SÍ, PERO ¿CÓMO?}

\section{Modificar radicalmente}

Por sí mismo considero que, ni siquiera encontrando la mejor formulación posible para un nuevo tipo de femicidio, ella por sí sola daría resultados satisfactorios si se colocara en un contexto de tutela de la vida como se dibuja en título VIII del libro II del vigente $C P$.

Los penalistas están acostumbrados a considerar los delitos contra las personas como un núcleo duro del Derecho penal, una especie de herencia del pasado que atraviesa los siglos sin precisar de modificaciones estructurales. Al ser formados, en todos los ordenamientos de nuestro entorno cultural, casi siempre por pocos elementos descriptivos y sin la presencia de elementos normativos que compliquen su interpretación, se suelen indicar como "delitos naturales" 41 . El príncipe de este grupo de tipos penales sería el homicidio, cuyo desvalor ontológico es tan evidente a toda persona que, como es sabido, en algunos ordenamientos de common law también se procesa por este crimen a niños de diez años o menos ${ }^{42}$.

40 “...si bien se logró acreditar que existía superioridad de fuerza, ya que la víctima medía 1,59 de altura y pesaba 59 kilos, mientras el acusado medía 1,80 y pesaba 80 kilos y de sexo, porque la víctima del ilícito es mujer y su agresor un hombre, se debe entender que estas características se encuentran comprendidas dentro del tipo penal, es por esto que el legislador le dio el nombre de femicidio, por lo que darle un carácter de agravar el hecho se caería en una suerte de infracción al principio non bis in idem, por lo que se rechaza esta agravante en contra del acusado...". STOP de Villarrica de 19.12.2011, citada por: Garita Vilchez, A.I., La regulación del delito de Femicidio /Feminicidio en América Latina y el Caribe, p. 36.

${ }^{41}$ Zaffaroni, E.R., et al., Derecho penal - parte general, II edición, Ediar, Buenos Aires, 2006, p. 11.

${ }^{42}$ Fornasari, G., Menghini, A., Percorsi europei di diritto penale, III edición, Cedam Padua, 2012, p. 64. 
Sin embargo, el desarrollo tecnológico ${ }^{43}$, por un lado, y los violentos cambios sociales ${ }^{44}$ y de valores sufridos por las sociedades occidentales después de la Segunda Guerra Mundial, por otro, desmienten hoy por completo tanto la afirmación de la inmutabilidad en el tiempo de esta herencia como la de la no influencia de factores culturales ${ }^{45}$.

No basta con decir que Chile precisa de un nuevo Código Penal, ya que así se podría pensar que el trabajo más importante sería, por ejemplo, la introducción de nuevos títulos dedicados a bienes jurídicos ignorados por completo en el siglo XIX, como el medio ambiente. En realidad, el trabajo troncal es la reforma de los ilícitos contra las personas que -no por casualidad- tanto el Proyecto 2014 como el "Anteproyecto de Código Penal Chileno” de 2005 elaborado por la Comisión Foro Penal (en adelante, Anteproyecto $2005^{46}$ ) pusieron al comienzo de la Parte Especial.

Centrando la atención solo en el tipo de homicidio, el desarrollo tecnológico, que nos brinda la posibilidad de salvar vidas gracias al trasplante de órganos, impuso introducir una nueva legislación extrapenal para indicar claramente el momento de la muerte de una persona. Del mismo modo, el hecho de que la medicina moderna asegure a todos una esperanza de vida más larga, hace posible que gran parte de la población piense su muerte no como un acontecimiento instantáneo, sino como un proceso dentro del cual tendrá que tomar decisiones. Se ve aquí cómo el cambio social, sumado al avance tecnológico, impone reconsiderar institutos presentes en el decimonónico Código chileno -como el auxilio al suicidio- que hace ciento cuarenta años tenían un papel muy distinto.

En este contexto, la introducción de un tipo de femicidio se puede leer como un fruto más de los muchos impulsos al cambio que desde hace tiempo recibe esta parte medular de la legislación penal. El femicidio, por su parte, se diferencia de los demás estímulos por la rapidez con la que se logró el resultado de su penalización. Lo anterior, sin embargo, está generando inesperados problemas porque al insertarse el tipo en la vieja cepa del Código de 1874, los resultados no se están mostrando satisfactorios.

Por tanto, para que Chile obtenga un tipo de femicidio que responda adecuadamente a los problemas que pretende enfrentar, tendrá que tener un tipo de homicidio que asuma

${ }^{43}$ El avance tecnológico permite clonar seres humanos y fecundar in vitro óvulos humanos; algo que hasta hace treinta años parecía ciencia ficción. Las legislaciones de muchos países se han adecuado, penalizando las conductas dañinas para los más importantes bienes jurídicos que ahora están al alcance de muchos centros médicos. Chile, sin embargo, no ha puesto suficientemente al día su legislación.

${ }^{44}$ Una concepción antropológica y sociológica que ve el Estado al servicio del ciudadano y no al revés y la centralidad recién tomada por los bienes de la vida y de la libertad de los individuos explican cómo los títulos dedicados a orden de la familia y moralidad pública hayan desaparecido de los Códigos reformados después de la Segunda Guerra Mundial. En legislaciones recién renovadas, delitos como el aborto y la violación se colocan necesariamente después del homicidio, respondiendo a una lógica que privilegia el aspecto de ofensa al individuo más que a la colectividad. De hecho, la doctrina desde hace tiempo ha adecuado la presentación de la materia al cambio de valores sociales: cfr. Politoff L., S., Matus A., J.P., Ramírez G., M.C., Lecciones de Derecho Penal Chileno - Parte Especial, II edición, Editorial Jurídica, Santiago, 2005, pp. 661-689.

45 A mi modo de ver, acerca de estos temas siempre es necesario remitirnos a las palabras de Mayer, M.E., Normas jurídicas y normas de cultura (trad. y prólogo de José Luis Guzmán Dalbora), Hammurabi, Buenos Aires, 2000, passim.

${ }^{46}$ Publicado en Política criminal, 1, D1, pp. 1-92. 
un papel central en la legislación penal y cuya pena sea un referente para las demás. En efecto, el delito lesiona la vida de las personas, el bien supremo del ordenamiento: hay que dejar al pasado la triste realidad actual en la que robar una vaca puede penarse más que matar a un hombre.

\section{Bases e instrumentos para la modificación}

A la luz de la necesidad de un cambio radical en la formulación del femicidio y de su conexión con los demás tipos dedicados a la tutela de las personas, las bases necesarias del trabajo de modificación tienen que ser, por un lado, los textos del Proyecto 2014 y del Anteproyecto 2005 y, por otro, el estudio, con los instrumentos del Derecho comparado, de la experiencia de otros países ${ }^{47}$.

Empezando por los primeros hay que aclarar que tan solo el Proyecto 2014 prevé un tipo específico de femicidio. Con todo, el Anteproyecto 2005 abrió camino a los redactores del sucesivo proyecto al poner en primer lugar (Art. 80), el tipo simple de homicidio que actualmente aparece en tercer lugar en la numeral $2^{\circ}$ del vigente artículo 391 CP. Así, el sucesivo artículo 81 establecía las hipótesis circunstanciadas (con un listado reducido respecto del actual artículo $391 \mathrm{~N}^{\circ} 1 \mathrm{CP}$ ), mientras que el parricidio, a pesar de las voces contrarias ${ }^{48}$, desaparecía.

Por su parte, el Proyecto 2014 dibuja un verdadero microsistema de tipos de homicidio completamente novedoso.

El tipo básico (Art. 211) se coloca en primer lugar, asignando una pena de privación de libertad de 6 a 15 años, en línea con la disposición actualmente vigente. A este sigue un artículo (212) inscrito bajo la rúbrica "Homicidio calificado", que recoge con modificaciones menores lo dispuesto por el actual artículo 391 N $^{\circ} 1$ CP. Los sucesivos dos artículos son una novedad absoluta: "Femicidio" (Art. 213) y "Homicidio intrafamiliar" (Art. 214), ambos penados con prisión de 10 a 20 años, como el homicidio calificado. En fin, el artículo 215 ("Agravantes") dispone la aplicación (con unas coletillas a efectos de evitar bis in idem) de las circunstancias señaladas en el artículo 212 como agravantes para los dos artículos anteriores ${ }^{49}$. El texto del artículo 213 es el siguiente:

47 De gran utilidad son los cuadros y gráficas elaborados por la publicación de Garita Vilchez, A.I., La regulación del delito de Femicidio /Feminicidio en América Latina y el Caribe, pp. 46-55; un análisis comparado de la legislación latinoamericana respecto de femicidio se encuentra en Corn, E., "La revolución tímida. El tipo de femicidio introducido en Chile por la Ley 20.480 en la perspectiva del Derecho comparado", en Revista de Derecho, Universidad Católica del Norte, vol. 21, n. 2, 2014, passim.

${ }^{48}$ De cierto interés, sobre todo a la luz de la propuesta de un tipo específico de "homicido intrafamiliar" (Art. 214) contenida en el Proyecto 2014, la propuesta de Jaime Retamal de no derogar derechamente el tipo de parricidio, sino de sustituirlo con una agravante especial del homicidio que, sin tener, como ahora, aplicación automática al constatarse el vínculo consanguíneo o conyugal, se aplicara a los casos en que realmente se diese "un reproche adicional a la comisión del homicidio". Retamal Herrera, J., "Intervención para agregar una circunstancia calificante por parentesco", en VV.AA. "Materiales de discusión presentados a la Comisión Foro Penal - Parte Especial”, en Política criminal, 1, D3, 2006, p. 10.

${ }^{49}$ Para facilitar consulta y cotejo se ofrece un extracto de las disposiciones publicadas en el Boletín No 9.274-07:

Libro Segundo - Título 1 (Delitos contra la vida y la salud) §1. Homicidio. 
Art. 213. Femicidio. Será sancionado con prisión de 10 a 20 años el varón que matare a la mujer que sea o haya sido su cónyuge, conviviente o pareja, cuando el hecho se haya cometido en razón de esa relación o vínculo.

En esta propuesta de reforma, el femicidio asume plena independencia del parricidio, el que, por su parte, se "transfigura" en el tipo de homicidio intrafamiliar. En este, el vínculo consanguíneo o conyugal ya no basta para integrar el delito, como ocurre en el vigente tipo de parricidio. Para pasar de un homicidio simple a uno intrafamiliar sería necesario abusar de la confianza y de la vulnerabilidad de la víctima y vivir bajo el mismo techo. Con la introducción de esta nueva figura delictiva, Chile seguiría el camino trazado por otros ordenamientos que han modificado, también en lo relativo a la justicia penal, su forma de considerar las relaciones familiares, pasando de privilegiar el aspecto formal a considerar primariamente el aspecto substancial ${ }^{50}$. Sin llegar al extremo de Alemania, en donde en principio matar al padre no es más grave que matar a otra persona cualquiera, Chile llegaría, por un camino distinto, al mismo resultado que se da ahora en España. El Código de 1995, como es sabido, derogó el parricidio pero mantuvo la circunstancia mixta de parentesco que los más altos tribunales españoles interpretan en un sentido sustancial: el parentesco no pesa en el juicio si la relación entre víctima y victimario se había esfumado con el transcurso del tiempo ${ }^{51}$. Con un catálogo de

Art. 211. Homicidio. El que matare a otro será sancionado con prisión de 6 a 15 años.

Art. 212. Homicidio calificado. La pena será de 10 a 20 años de prisión, si el bomicidio fuere cometido:

$1^{\circ}$ con alevosía, entendiéndose que la hay cuando se obra a traición o provocando la indefensión de la víctima;

$2^{\circ}$ por codicia;

$3^{\circ}$ con ensañamiento, aumentando deliberada e inbumanamente el dolor de la víctima;

$4^{\circ}$ para facilitar o encubrir la comisión de otro delito.

Si concurriere más de una de las circunstancias precedentes se considerará cualquiera para calificar el homicidio y se estimará las demás como agravantes.

Art. 213. (omissis - véase arriba en el texto\}.

Art. 214. Homicidio intrafamiliar. El que, abusando de la confianza o de la vulnerabilidad de la víctima, matare a su cónyuge o conviviente, a un pariente por consanguinidad o por afinidad en toda la línea recta o en la colateral hasta el tercer grado inclusive que viva bajo el mismo techo, o a una persona menor de 18 años, mayor de 70 años o discapacitada que se encuentre bajo el cuidado o dependencia propios o de cualquier integrante de la familia y que viva bajo el mismo techo, será sancionado con prisión de 10 a 20 años.

Art. 215. Agravantes. En los casos de los artículos 213 y 214, la concurrencia de cualquiera de las circunstancias señaladas en los números 2 a 4 del artículo 212 será estimada por el tribunal como una agravante. Lo mismo hará el tribunal en el caso del artículo 213, cuando concurriere la circunstancia señalada en el número 1 del artículo 212.

${ }^{50}$ Ya se citaron más arriba las consideraciones de Van Weezel de la Cruz, A., "Lesiones y violencia intrafamiliar", p. 224 y Scheechler Corona, C., "El cónyuge y el conviviente en el Código Penal chileno”, p. 43.

${ }^{51}$ En España -según lo que refiere Mir Puig (Mir Puig, S., Derecho penal. Parte general, VIII edición, Reppertor, Barcelona, 2008, pp. 635-636)- la circunstancia mixta de parentesco (artículo 23 CPEsp.) como agravante es tomada en cuenta por el Tribunal Supremo tan solo cuando no ha "perdido su significado de vinculación entre los parientes”. Es el mismo texto de la norma española (modificado por última vez en 2003) el que favorece esta interpretación, en cuanto habla de "ser o haber sido el agraviado cónyuge o persona que esté o haya estado ligada de forma estable por análoga relación de afectividad”. Confirma esta interpretación con abundantes citas de jurisprudencia: Goyena Huerta, J., "De la circunstancia mixta de parentesco", en Gómez Tomillo, M. (dir.), Comentarios al Código Penal, II edición, Lexnova, Valladolid, 2011, pp. 222-223. 
agravantes y atenuantes reducido al máximo, en línea con el Anteproyecto 200552, y la desaparición de la circunstancia mixta de parentesco ${ }^{53}$, para alcanzar el mismo resultado los redactores del Proyecto 2014 tuvieron que dibujar un tipo específico.

Veo con gran favor la separación del femicidio del homicidio intrafamiliar. Si bien es cierto que la violencia de género y la violencia intrafamiliar tienen muchísimos puntos de contacto e intersección, se trata de dos fenómenos distintos ${ }^{54}$ que hay que tratar por separado.

Obviamente, en abstracto, el homicidio de la cónyuge que vive bajo el mismo techo puede castigarse, según el Proyecto, tanto sobre la base del artículo 214 como a base del 213, pero el móvil marcará diferencia. Así, el marido que mata a su mujer porque él tiene a escondidas a una amante y quiere escaparse con esta comete un homicidio intrafamiliar, porque su esposa no espera que su pareja pueda convertirse en un agresor y actúa siempre, respecto de él, con plena confianza. En cambio, el marido que mata a su mujer porque ella tiene a un amante y no quiere que se vaya con este, actúa para preservar el vínculo que tiene con ella (el artículo 213 justamente habla de "hecho cometido en razón de la relación o del vínculo"). En este caso, incapaz de aceptar el fin de la relación sentimental, el hombre comete un delito en contexto de violencia de género y los redactores correctamente ocuparon la palabra "femicidio".

En primer lugar, tomando en la debida cuenta los estímulos de la doctrina y de las instituciones internacionales, los miembros de la comisión centraron el injusto material del femicidio ya no en el vínculo familiar o cuasifamiliar entre víctima y victimario, sino en la relación en sentido amplio. En segundo lugar, la propuesta de reforma incluye situaciones de femicidio no íntimo ${ }^{55}$ : en efecto, la disposición, en el listado de posibles sujetos pasivos indica no solo a la cónyuge y a la conviviente, sino también a la "pareja", que puede no haber vivido ni siquiera un día bajo el mismo techo del victimario, como ocurre con los "pololos".

Sin embargo, la abertura de la nueva disposición -lamentablemente- no sería total porque quedarían excluidos del tipo (y de la mayor sanción respecto del homicidio simple) los que la doctrina llama "femicidios en el ámbito público", es decir, "aquellos en los que el autor es un extraño o un conocido que no forma parte del entorno doméstico de la mujer asesinada" 56 .

52 Véase: Ramírez Guzmán, M.C., “Anteproyecto de Código Penal...”, passim.

53 Con buena paz de Pacheco y de su modelo aplicativo de esta circunstancia, interesante espejo de la realidad social de su tiempo: Pacheco, J.F., El Código Penal Concordado y Comentado, Imprenta de Manuel Tello, Madrid, 1867, p. 214 ss.

${ }^{54}$ Cfr. Corcoy Bidasolo, M., "Problemática jurídico-penal y político-criminal de la regulación de la violencia de género y doméstica”, pp. 305 y 310; Corn, E., "El tipo de femicido entre violencia intrafamiliar y violencia de género. Reflexiones para un debate europeo a partir de la experiencia chilena”, en Pérez Álvarez, F., (dir.), III Congreso Internacional de Jóvenes Investigadores en Ciencias Penales (Actas) - Salamanca, 17/19.06.2013, Ediciones Universidad de Salamanca, Salamanca (España), 2014, (en prensa), p. 2.

55 Véase arriba la nota 17.

56 "Entre las formas más frecuentes se mencionan las muertes violentas vinculadas a agresiones sexuales y los asesinatos en serie por motivos misóginos o relacionados con la elaboración de material pornográfico con 
Otro instrumento básico para el trabajo de modificación de las normas vigentes es el Derecho comparado. Esta disciplina tiene una corta tradición en Latinoamérica y su metodología no es objeto de enseñanza generalizada en las Universidades ni en el pre ni posgrado. Por esto, incluso en trabajos que pretenden ser científicos, a veces se indican como comparación simples referencias a la legislación de otros países sin ninguna profundización respecto del contexto normativo, jurisprudencial o social en el que se colocan las disposiciones citadas ${ }^{57}$. De poco sirve, en el contexto de este artículo, un largo o corto listado de las decenas de leyes promulgadas en las últimas décadas en el continente para tratar de colmar la enorme desigualdad que separa los géneros; mucho más útil es un análisis profundizado ${ }^{58}$ que considere todos los formantes del Derecho ${ }^{59}$.

\section{LA PROPUESTA}

1. Texto

En mi opinión, exactamente como propusieron el Anteproyecto 2005 (Art. 80) y el Proyecto 2014 (Art. 211), el Libro segundo del renovado Código Penal chileno debería abrirse con un artículo dedicado al tipo básico de homicidio. Su pena debería ser la segunda más alta entre las admitidas en la Parte General, dejando espacio en la escala gradual a un primer escalón destinado para la sanción de los homicidios calificados.

$\mathrm{Ni}$ el femicidio ni el homicidio intrafamiliar deberían preverse como tipos específicos, porque esto complicaría demasiado el cuadro. Considero que ambas situaciones deben canalizarse vía circunstancias agravantes contenidas en un único artículo que establezca las diferentes hipótesis de homicidio calificado.

De este modo, la agravante de femicidio (como la de "parentesco substancial") acompañaría a las conocidas e indiscutidas circunstancias de alevosía, codicia y ensañamiento. La pena prevista debiese llegar al nivel más alto de la escala ${ }^{60}$.

componentes sádicos”: Laurenzo Copello, P., “Apuntes sobre el feminicidio”, p. 124. Otro triste "clásico” es el homicidio de prostitutas.

${ }^{57}$ David, R., Le droit comparé: droits d'hier, droits de demain, Economica, París, 1982, passim; Pradel, J., Droit pénal comparé, III edición, Dalloz, París, 2008, passim; Fornasari, G., "Conquiste e sfide della comparazione penalistica”, en Dolcini, E., Paliero, C.E., (dir.), Studi in onore di G. Marinucci, Giuffrè, Milán, 2006, pp. 265 ss.

${ }^{58}$ Un intento en este sentido se ofrece en: Corn, E., "La revolución tímida. El tipo de femicidio introducido en Chile por la Ley 20.480 en la perspectiva del Derecho comparado”, passim.

59 Sacco, R., "Legal Formants: A Dynamic Approach to Comparative Law (Installment I of II)", en The American Journal of Comparative Law, vol. 39, n. 1 (Winter), 1991, passim y vol. 39, n. 2 (Spring), 1991, passim.

${ }^{60}$ Soy de la opinión que dicha pena podría ser la cadena perpetua, en la medida en que su aplicación se realizara dentro de los límites cristalizados por las sentencias de los Tribunales Constitucionales de Alemania, Francia e Italia y no mirando al modelo estadounidense. En Alemania, el artículo 38 del StGB admite en el ordenamiento la pena de cadena perpetua (Lebenlange Freibeitstrafe), estableciendo, al mismo tiempo, en 15 años la duración máxima para la pena privativa de libertad no perpetua. Sin embargo, es necesario interpretar la norma en combinación con el artículo 57 a) del mismo Código y el fallo del Bundesverfassungsgeright 21 de junio de 1977, $B \operatorname{Ver} G e$ 45, 187 -en castellano véase: Consejo General del Poder Judicial (CGPJ), Informe sobre el 
La propuesta de redacción para la circunstancia de femicidio sería:

por odio de género o en contexto de violencia de género, entendiéndose por este toda conducta, acción u omisión, que de manera directa o indirecta, tanto en el ámbito público como privado, basada en una relación desigual de poder, afecte la vida, libertad, integridad física, psicológica, sexual, económica o patrimonial de la mujer. Quedan comprendidas también las perpetradas desde el Estado o por sus agentes.

Aunque corresponda solo parcialmente a los fines de esta propuesta, es imprescindible señalar que, según los convenios internacionales más recientes ${ }^{61}$, también debería evaluarse la posibilidad de prever como elemento de agravación el hecho que el delito lo presencien los hijos de la víctima que sean menores de edad ${ }^{62}$.

\section{Fundamentación y críticas}

En primer lugar hay que justificar por qué es preferible la circunstancia respecto del tipo específico. La razón es simple: la conducta en sí, tanto en el homicidio como

Anteproyecto de Ley Orgánica de medidas de reforma para el cumplimiento integro y efectivo de las penas (4 de febrero de 2003). Disponible en_<http://www.poderjudicial.es/cgpj/es/Poder_Judicial/Consejo_General_del_Poder_Judicial/ Actividad_del_CGPJ/Informes>, 2003,p. 6-. En este, los jueces afirmaron que la pena perpetua era necesaria para mantener en la ciudadanía la conciencia del Derecho frente a delitos especialmente graves con un extraordinario contenido de ilicitud y culpabilidad. En estos casos, incluso las consideraciones humanitarias ceden paso a la prevención general. Para la Corte de Karlsruhe queda firme, sin embargo, para no salir de los estrechos límites de la Grundgesetz, la prohibición de perjudicar la dignidad humana. En la certeza que las penas de larga duración crean graves disturbios en la personalidad del condenado -según lo que se afirma en el fallo (y como sostiene también la doctrina de habla hispana: Mir Puig, S., Derecho penal. Parte general, pp. 123 y 687)-, la ejecución de la cadena perpetua tiene que realizarse teniendo la debida consideración del reo como persona. Por esto el artículo 57 a) $S t G B$ establece en 15 años el término a partir del cual el juez, si se satisfacen una serie taxativa de requisitos, podrá conceder libertad condicional. En Italia, este mismo término es de 26 años (Art. 176 ap. III CP); en Francia es de 18 años, los que pueden aumentarse a 22 (Art. 132-23 CP). Además de compartir la posición del supremo tribunal alemán, considero que una postura similar ofrece mayores garantías contra el aumento continuo y exagerado del máximo de pena privativa de libertad. En efecto, varios países de Latinoamérica que no tienen cadena perpetua establecen, en la actuación práctica de sus legislaciones, límites para la pena máxima más altos de los que vimos en los citados Estados europeos (por ejemplo Colombia, México y Brasil). Ocurre lo mismo hasta en España, en donde solo recién se está abriendo debate acerca de la cadena perpetua (en virtud del anteproyecto de reforma al Código Penal de 2012-2013 que incluye la nueva pena de prisión permanente revisable), pero mucho después que las reformas de la Ley Orgánica 7 de 2003 subieran en unos casos el límite para el acceso a la libertad condicional a 35 años (Arts. 76 y 78 CP) (García Albero y Tamarit Sumalla, La reforma de la ejecución penal, Tirant lo Blanch, Valencia, 2004, pp. 44 y 88).

${ }^{61}$ Cfr. Art. 46 letra d) Convenio de Estambul. Nótese, además, como esta es una de las circunstancias (letra $g$ )) en la que se puede manifestar el delito de femicidio en Guatemala según el artículo 6 del Decreto 22 de 2008.

${ }^{62}$ La violencia, sobre todo si se manifiesta en el ámbito de la familia, produce daños en los menores de edad no solo cuando ellos padecen golpes que producen lesiones físicas, sino también cuando asisten a actos violentos cuyas víctimas directas son otros seres queridos. Presenciar estas violencias puede producir daños psicológicos inmediatos o a mediano o largo plazo en la estabilidad emotiva del niño. El fundamento de la agravación de pena sería, por tanto, el cálculo, entre los sujetos pasivos, no solo del individuo que padece de violencia física, sino también de los menores que sufren por la violencia psíquica. 
en el femicidio, es la misma, es decir, matar. Pasar de un tipo específico, como ocurre ahora -aunque de forma no plena-, a una circunstancia agravante no significaría un deterioro del carácter simbólico propio del Derecho Penal, pues se seguiría ocupando la palabra femicidio (como pasa en Argentina) e incluso quedaría explícito su efecto jurídico. La decisión de prever un listado más largo de circunstancias para el homicidio agravado, además, también sería más fructífero en el plano técnico porque permitiría una mayor fluidez en el cálculo de la pena al concurrir varias agravantes (por ejemplo femicido y ensañamiento $)^{63}$. Precisamente por lo anterior, el Proyecto 2014, con un artículo ad hoc (215) para las agravantes del femicidio y del homicidio intrafamiliar, parece a este respecto algo farragoso ${ }^{64}$.

En segundo lugar, hay que tener en cuenta las razones que hicieron descartar otros modelos y empujaron a una solución semejable a la de Argentina ${ }^{65}$.

El modelo costarricense ${ }^{66}$-con un tipo de femicidio de alcance muy reducido, que simplemente desincorpora del parricidio los casos en los que la víctima estaba casada o era conviviente del victimario- fue de referencia para el legislador chileno de 2010. Ya se indicaron todos los defectos de esta opción y las razones por las que hay que buscar alternativas.

La legislación guatemalteca, que fue modelo para las sucesivas de Nicaragua y El Salvador, concentra sus mayores virtudes en el hecho de centrarse en la tutela de la mujer como tal, sin la necesidad que sea la madre, cónyuge o conviviente del agresor, y en el hecho de introducir, como elemento relevante de la disposición, la desigual relación de poder entre víctima-mujer y victimario-hombre. Esto es, en efecto, lo que caracteriza desde el punto de vista sociológico y antropológico al femicidio ${ }^{67}$ y lo distingue de un simple homicidio en el que muere una mujer.

\footnotetext{
${ }^{63}$ Según lo que se escribió en el título de este artículo, esta propuesta de reforma se ofrece en el contexto de un nuevo Código Penal para Chile y entrar en detalle en la solución del concurso de calificantes no corresponde al objetivo de este trabajo. Sin embargo, se puede auspiciar una simplificación del cuadro actual, siendo conscientes del hecho que, al aumentar la pena del homicidio simple, en todo caso, al ocurrir hasta dos circunstancias agravantes, otras podrían perder su efecto agravatorio (y lo mismo se da hoy con el artículo 390 ap. II CP). No hay que perder nunca de vista, sin embargo, la lección de Politoff, Bustos y Grisolía que -en materia de calificantes para casos de parricidio e infaticidio- escribían: "Para quienes estamos convencidos del carácter instrumental del Derecho Penal al servicio de necesidades prácticas de la sociedad, no será permisible que un solo ser humano, por excepcional que sea el caso imaginado, sufra una pena absurdamente desproporcionada, solo en obsequio a razones de equilibrio formal o de mera sistemática" (Politoff, S., Grisolía F., Bustos, J., Derecho penal chileno. Parte Especial. Delitos contra el individuo en sus condiciones físicas, Editorial Jurídica, Santiago, 1992, p. 110.

${ }^{64}$ Una redacción más simple podría ser: "En los casos de los artículos 213 y 214, la concurrencia de las circunstancias señaladas en el artículo 212 será estimada por el tribunal como una agravante”, pues el número 1 del artículo 212, en un caso de homicidio intrafamiliar, siempre resultaría absorbido. Es más, dicha disposición, en lugar de albergar en un artículo autónomo, podría aparecer al final del mismo artículo 212.

${ }^{65}$ Véase: Buompadre, J.E., "Los delitos de género en la reforma penal...”, passim y Puricelli, J.L., "Violencia de género. Reflexiones sociológicas y jurídicas”, en Revista de Doctrina Judicial, XXIX, 42, 2013, passim.

${ }^{66}$ La división en modelos refleja la presentada en el trabajo de Corn, E., "La revolución tímida. El tipo de femicidio introducido en Chile por la Ley 20.480 en la perspectiva del Derecho comparado”, passim.

${ }^{67}$ De referencia los escritos de la atropóloga mexicana Marcela Lagarde, que participó como perita de las víctimas en el caso González y otras vs. México, conocido como "Campo Algodonero", resuelto por la Corte
} 
Lo que principalmente dificulta para adoptar la ley guatemalteca como ejemplo a seguir es el hecho de que la disposición está escrita, más bien, como las que se encuentran en las acts de los países de common law y no como los artículos de los Códigos de los países de civil law. La norma se divide en dos partes: la primera describe la conducta (...en el marco de las relaciones desiguales de poder entre hombres y mujeres, diere muerte a una mujer... $\left.{ }^{68}\right)$, mientras que la segunda detalla, más que circunstancias, verdaderos contextos en los que se tiene que desarrollar la violencia. Se replica así, pero al revés, el esquema conocido en el Derecho penal internacional en que los tipos de parte especial tienen un "elemento de contexto"69 al que sigue un largo listado de conductas sancionadas. Una norma de esta factura se adaptaría mal al resto de la legislación chilena, sin considerar que la ley guatemalteca contiene muchas subhipótesis que por fortuna se dan solo excepcionalmente en el medio chileno, como el asesinato en ritos grupales o la mutilación de la víctima y, de ocurrir, resultaría más adecuado enfrentarlas recurriendo a otras circunstancias, como el ensañamiento.

La propuesta aquí formulada se inspira en la solución argentina que, reformando en el Código Penal la disposición relativa al homicidio agravado (Art. $80 \mathrm{CP})^{70}$ introdujo dos nuevos numerales (el $\mathrm{N}^{\circ} 11$ y el $\mathrm{N}^{\circ} 12$ ) modificando de manera importante también el $\mathrm{N}^{\circ} 1$ (circunstancia de parricidio) y el $\mathrm{N}^{\circ} 4$ (circunstancia de odio) ${ }^{71}$. En la propuesta sustentada acá se funden en una sola disposición el núcleo de la circunstancia de odio por razones de género y una reformulación de la circunstancia para situaciones de violencia de género del numeral $\mathrm{N}^{\circ} 11^{72}$. El legislador trasandino probablemente evitó introducir un tipo específico de femicidio simplemente porque ni siquiera tiene, en su Código Penal, una figura de parricidio, y todas las hipótesis agravadas de homicidio (Art. 79 CP) se encuentran en el (largo) listado del artículo 80 CP. El tipo de modificación aportado con la Ley 26.791 de 2012 ha sido, por lo tanto, plenamente acorde con el contexto legislativo preexistente. En todo caso, el resultado, desde el punto de vista sistemático parece fluido y más apropiado para enfrentar de modo armónico el problema respecto de las otras posibilidades presentadas.

En tercer lugar, hay que dar cuenta en detalle del texto de la agravante propuesta.

Opté por unir una agravante por odio hacia el género con una dedicada a la violencia de género porque, aunque se trate de fenómenos que en algunos casos podrían diferir,

Interamericana de Derechos Humanos en su sentencia de noviembre de 2009. Cfr. Lagarde y de los Ríos, M., Los cautiverios de las mujeres. Madresposas, monjas, putas, presas y locas, IV edición, coedición CEIICH-UNAM, Ciudad de México, 2005, passim; Corte IDH (González y otras vs. México) passim; Corte IDH, Caso González y otras vs. México, Sentencia de 16 de noviembre de 2009, Serie C No 205, passim.

${ }^{68}$ Guatemala: arículo 6 del Decreto 22 de 2008.

69 Ambos, K., La parte general del Derecho penal internacional. Bases para una elaboración dogmática (trad. y prólogo de Ezequiel Malarino), Fundación Konrad Adenauer, Montevideo, 2005, pp. 21 y 75-79.

${ }^{70}$ Ley 26.791 de 2012.

${ }^{71}$ Zaffaroni, E.R., “Observaciones sobre la delincuencia por odio en el Derecho Penal argentino”, pp. 1747-1748.

${ }^{72} \mathrm{La}$ circunstancia de parentesco se modificó añadiendo a los excónyuges o a las personas con quien el autor ha mantenido una relación de pareja, aunque no hubiese convivencia. Se considera que la legislación de Argentina admite el matrimonio de personas del mismo sexo (Ley 26.618 de 2010). La circunstancia de venganza transversal (Art. $80 \mathrm{~N}^{\mathrm{o}} 12 \mathrm{CP}$ ) se deja al margen de esta disertación por considerarla parcialmente ajena al discurso. 
están pensadas con el fin de sancionar con mayor gravedad las conductas más violentas cometidas contra aquella mitad de la sociedad chilena (y mundial) que solo recién se está liberando del liderazgo social, político y cultural del sexo masculino. La agravante por odio hacia el género hoy está incluida en el grupo contenido en la circunstancia genérica de discriminación del artículo $12 \mathrm{~N}^{0} 12 \mathrm{CP}^{73}$. Aunque la discusión parlamentaria de la Ley 20.609 de 2012 empezó en 2005 el Anteproyecto 2005 no contiene referencias a la circunstancia discriminatoria ${ }^{74}$, mientras que el Proyecto 2014 cita explícitamente la discriminación, pero solo en el contexto de una agravante aplicable a los delitos contra la paz, la seguridad y el bienestar de la humanidad (Título XVII - Art. 654). Al respecto opino que la agravante por discriminación podría derogarse del ordenamiento penal chileno solo si se pasara a una mejor solución, como sería la de un delito específico de discriminación ${ }^{75}$. Sin embargo, pienso también que a este nuevo ilícito penal ad hoc debería acompañarse la agravante por odio de género de esta propuesta, porque, de todas la diferentes formas que ha asumido y asume la discriminación como fenómeno, la de género tiene importantes peculiaridades $(v, g r$. no se da hacia una minoría, ni en épocas históricas específicas y tiene difusión prácticamente global). Evidentemente, en caso de aplicación de la agravante, no se condenaría también por el delito específico de discriminación realizándose un típico ejemplo de concurso aparente de normas ${ }^{76}$.

Pasando a examinar la parte de la agravante dedicada a la violencia de género, hay que precisar que, en mi opinión, la definición de esta forma de violencia estaría mejor situada en la parte inicial de una ley específicamente dedicada a la violencia en contra de las mujeres. Esta norma tendría el papel central y la finalidad interpretativa general que, en el contexto de la Ley 20.066 de 2005, es ocupado por el artículo 5. Sin embargo, la diferencia abismal entre la norma que se acaba de citar y la definición de violencia de género contenida en esta propuesta explica por sí sola la imposibilidad de reconducir la violencia de género en el ámbito de la VIF, por ejemplo, proponiendo modificaciones menores del mismo artículo 5. Tanto precisaba Chile de una ley para la violencia en ámbito familiar antes de tener a la Ley 20.066 de 2005, como sigue precisando hoy de una ley de violencia contra la mujer ${ }^{77}$. En efecto, todo intento de aumentar la tutela de

\footnotetext{
$73 \mathrm{Al}$ respecto se entiende citada la doctrina señalada arriba en la nota 26.

${ }^{74}$ Se puede imaginar que tan solo se habría podido aplicar a ciertos casos de discriminación el artículo 252 (el tipo puesto al comienzo del párrafo dedicado a los abusos contra particulares - Título IX / Delitos contra la Administración Pública-) según el cual comete ilícito penal el [...] funcionario público que, desempeñando un acto del servicio, cometa cualquier vejación injusta contra las personas [...]. La norma, es factible precisar, lejos de ser novedosa, se inspira claramente en el vigente artículo $255 \mathrm{CP}$.

${ }^{75}$ Se trata de la opción elegida también por el maestro Politoff (Politoff, S., "Informe sobre los delitos de discriminación en el derecho penal comparado (a la luz del Proyecto de Ley sobre discriminación racial y étnica (Boletín No 2142-17)", en Ius et Praxis, 5, No 2, 1999, p. 211). Detallo más mi postura en Corn, E., “Apuntes acerca del problema de la discriminación y de su tratamiento penal", passim.

${ }^{76}$ Etcheberry, A., Derecho Penal - Parte general, III edición, Tomo II, Editorial Jurídica, Santiago, 1998, p. 122.

77 Cfr. Garita Vilchez, A.I., La regulación del delito de Femicidio /Feminicidio en América Latina y el Caribe, p. 47. En el Cuadro 2 esta autora indica la leyes que los distintos Estados del continente introdujeron en los últimos años para penalizar la violencia contra la mujer. En las casillas dedicadas a Chile Garita puede indicar tan solo la ley que reformó los delitos sexuales $\mathrm{N}^{\circ} 19.617$ de 1999. Es cierto que aquel intervención del Parlamento fue un
} 
las personas de sexo femenino mediante la modificación de la ley de 2005 produciría resultados estériles: ¿qué tiene que ver la violencia de un hijo contra su padre mayor, con el que convive, con la de un "expololo" contra la mujer que ya no quiere estar con él? Nada: la forma de manifestación de la violencia puede ser la misma, mientras que es cierto que las dos conductas nacen de contextos distintos y precisan de respuestas legislativas específicas. Por tanto, mientras falte una ley ad hoc, la definición de violencia de género deberá contenerse en la norma penal ${ }^{78}$.

Además, a efecto de redactar la definición de violencia de género para la propuesta formulada en este artículo se tomó como referencia una ley para la mujer y no una para la familia; en concreto: la "Ley de protección integral a las mujeres" de Argentina (Ley $N^{o} 26.485$ de 2009). Estamos convencidos que la definición ofrecida es suficientemente taxativa como para no violar el principio de legalidad, y su innegable amplitud se explica, además se justifica, a partir de la naturaleza amplia y compleja del fenómeno de la violencia de género que el texto de la disposición tiene que abarcar en su totalidad ${ }^{79}$.

Sin embargo, en fin, si no viola el principio de legalidad, es cierto que la agravante propuesta incide de forma importante en materia de garantías constitucionales de igualdad formal de hombres y mujeres ante la ley, modificando los equilibrios que la Ley 20.480 de 2010 había logrado mantener inalterados ${ }^{80}$, pero a costa de trocar la protección de la mujer (que era el objetivo esperable tras la introducción de un tipo de femicidio) con una mayor tutela de la familia.

gran avance respecto de la situación anterior (véase: Rodríguez Collao, L., Delitos sexuales, passim), sin embargo, basta con leer los títulos de las leyes de otros países para enterarse cómo en el exterior diputados y senadores supieron dibujar instrumentos mucho más ambiciosos. Dos simples ejemplos: la "Ley general de acceso de las mujeres a una vida libre de violencia”, en México (ley publicada el 1 de febrero de 2007) y la Ley 26.485 de 2009 de Argentina, cuyo título completo es: "Ley de protección integral para prevenir, sancionar y erradicar la violencia contra las mujeres en los ámbitos en que desarrollen sus relaciones interpersonales".

${ }^{78}$ Otra posibilidad habría sido la de proponer la migración de las normas acerca de femicidio en una futura ley específica para el derecho de las mujeres a una vida libre de violencia. Una ley con este fin -se insiste- es necesaria y deseable, pero soy de la opinión que el femicidio (como las lesiones físicas, psíquicas y a la integridad sexual) deberían reformarse permaneciendo en el Código, que es el lugar prepuesto a la recopilación de las normas sancionatorias contra los bienes jurídicos más relevantes como son la vida, la integridad física y sexual de las personas (prescindiendo de su sexo). Además, la "huida" desde el Código favorece el fenómeno de la desproporción en la sanción de conductas similares y dificulta el acceso a la información jurídica para los que no son especialistas.

${ }^{79} \mathrm{La}$ extensión del concepto de violencia de género hasta incluir situaciones de afectación "simplemente" económica o patrimonial de la mujer no tiene que extrañar aunque se proponga como calificante de un delito contra la vida. La sujeción de un sujeto a otro se puede manifestar de múltiples formas y un ejemplo puede ser despojar sistemáticamente a una mujer de su sueldo, privándola así de su independencia económica. Si el hombre, no satisfecho con esto, mata a su mujer (por ejemplo, porque ella consigue crearse una cuenta paralela para no perder su sueldo) es correcto que esto se configure como femicidio, no solo sociológica sino también jurídicamente. En la actualidad, entre sujetos que no convivieron o no se casaron, dicha conducta se castigaría como homicidio en concurso con extorsión, lo que no nos parece satisfactorio y ajustado a la realidad del fenómeno. Desde el punto de vista dogmático, no hay obstáculos a agravar delitos contra la vida con ofensas contra el patrimonio, pues en la mayoría de los países hurtos y robos son calificantes de los homicidios. Chile, con sus normas relativas al robo con homicidio, representa una excepción en sentido inverso.

${ }^{80}$ Ya se citó al respecto a Toledo Vásquez, P., "Leyes sobre femicidio y violencia contra las mujeres”, p. 45. 
Así, si la agravación por odio hacia el género no crea problemas ${ }^{81}$, la parte de la circunstancia dedicada al contexto de violencia de género parece tener una lectura conforme a Constitución ${ }^{82}$ más difícil de argumentar.

Sin embargo, dicha dificultad es solo aparente, porque la igualdad formal ante la ley no es un principio absoluto en ningún ordenamiento, pudiéndose balancear con otros valores si detrás de la opción hay una motivación adecuada ${ }^{83}$. Chile, de hecho, recurre a sanciones diferenciadas para tutelar personas discriminadas en razón de otros factores, por ejemplo, considerando falta "la discriminación manifiesta e intencionada en contra de los indígenas, en razón de su origen y su cultura" ${ }^{84}$. La agravante que se propone se centra en otra diferencia entre personas que genera discriminación: el sexo. Se trata de una diferencia tan presente y radicada en la sociedad como para justificar un trato diferenciado en el ámbito penal. El marido que mata a su cónyuge -a la que impuso una dependencia social y económica que, de hecho, le impidió una posibilidad real de pedir ayuda para salir de su condición de inferioridad- merece una sanción más enérgica, exactamente igual a la del homicida que actúa sobreseguro. En ambos casos el autor se encuentra en una situación de ventaja respecto de la víctima de la que se aprovecha para realizar el delito.

Lo más importante -y lo que permitiría superar las críticas del Tribunal Constitucional- es que la agravante no se podría atribuir a un imputado en todos los casos en los que la víctima sea mujer, sino tan solo ${ }^{85}$ en aquellos en donde la conducta contextual -manteniéndose dentro de las fronteras de un Derecho penal "de acto" y no "de la intención"- se basa efectivamente en la relación desigual de poder entre el hombre-autor y la mujer-víctima.

${ }^{81}$ El odio del varón hacia el género femenino tiene una específica palabra, "misoginia”, mientras que no hay una para su opuesto. Sin embargo, se puede imaginar (y se ha dado en diversos países) el caso de la prostituta que, después de contraer SIDA, desarrolla un odio profundo hacia el género masculino y decide tener relaciones sexuales sin protección alguna con sus clientes con el fin que ellos se enfermen del mismo mal y mueran. A situaciones como esta se podría aplicar la circunstancia propuesta (justificada por el hecho de que la mujer no tiene consideración alguna para sus víctimas que pretende matar por el hecho de ser hombres) y por lo tanto cae cualquier cuestionamiento de constitucionalidad por violación del principio de igualdad formal entre los géneros.

82 Obligatoria la referencia a Bricola, F., Teoría general del delito (trad. de Diana Restrepo Rodríguez), BdeF, Montevideo-Buenos Aires, 2012, passim; Ferrajoli, L., "La differenza sessuale e le garanzie dell'uguaglianza", en Democrazia e Diritto, 2, 1993, passim; en la doctrina de habla hispana: Díez Ripollés, J.L., La racionalidad de las leyes penales, Trotta, Madrid, 2003, passim; en el medio nacional: Fernández Cruz, J.A., "El juicio constitucional de proporcionalidad de las leyes penales: ¿la legitimación democrática como medio para mitigar su inherente irracionalidad?", en Revista de Derecho, Universidad Católica del Norte - Coquimbo, XVII, 1, 2010, pp. 73-87.

${ }^{83}$ La doctrina de la Corte costituzionale italiana, que ha dedicado muchos fallos a estos problemas, habla al respecto de principio di ragionevolezza ("principio de sensatez"). Cfr. Insolera, G., "Principio di eguaglianza e controllo di ragionevolezza sulle norme penali”, en Insolera, G., Mazzacuva, N., Pavarini, M., Zanotti, M. (dir.), Introduzione al sistema penale, IV edición, Tomo I, Giappichelli, Torino, 2012, pp. 401-407 y 419-420.

${ }^{84}$ Así sigue la disposición: "El que incurriere en esta conducta será sancionado con multa de uno a cinco ingresos mínimos mensuales”. Artículo 8, Ley 19.253 de 1993.

${ }^{85}$ Según las sugerencias también de la doctrina argentina: Buompadre, J.E., “¿Es necesario acreditar en el proceso la 'posición de dominio o actitud machista' en casos de violencia de género? Especial referencia al delito de femicidio", en Revista pensamiento penal, No 158, disponible en: <www.pensamientopenal.com.ar>, 2013, p. 8. 


\section{BiBLIOGRAFÍA}

Амвоs, K., La parte general del Derecho penal internacional. Bases para una elaboración dogmática (trad. y prólogo de Ezequiel Malarino), Fundación Konrad Adenauer, Montevideo, 2005, 594 pp.

Bricola, F., Teoría general del delito (trad. de Diana Restrepo Rodríguez), BdeF, MontevideoBuenos Aires, 2012, 369 pp.

Buompadre, J.E., “¿Es necesario acreditar en el proceso la 'posición de dominio o actitud machista' en casos de violencia de género? Especial referencia al delito de femicidio", en Revista pensamiento penal, $\mathrm{N}^{\circ} 158$, disponible en: <www.pensamientopenal.com.ar>, 2013, pp. 1-8 [fecha de visita: 24 de abril de 2014]

Buompadre, J.E., "Los delitos de género en la reforma penal (Ley 26.791)", en Revista pensamiento penal, $\mathrm{N}^{\circ} 152$, disponible en: <www.pensamientopenal.com.ar>, 2013, pp. 1-43 [fecha de visita: 24 de abril de 2014]

Car Silva, M., "Comentario a la sentencia definitiva condenatoria dictada por el sexto tribunal oral en lo penal de Santiago por el delito de femicidio frustrado y otros", en Revista jurídica del ministerio público, LV, junio, 2013, pp. 165-179.

Castañeda Meneses, P., Urquieta Álvarez, M.A., Donoso Pinochet, M., Estudio exploratorio sobre relaciones de pareja en adolescentes desde la perspectiva de la violencia basada en el género, Universidad de Valparaíso-Seremi Región de Valparaíso, Valparaíso, 2012, 46 pp.

COMITÉ CEDAW, Observaciones finales sobre los informes periódicos quinto y sexto de Chile, adoptadas por el Comité en su $53^{\circ}$ período de sesiones ( $1^{\circ}$ a 19 de octubre de 2012) (CEDAW/C/CHL/CO/5-6). Disponible en: <http://acnudh.org/wp-content/uploads/2013/01/CEDAW-Chile-2012-ESP. pdf >, 2012, [fecha de visita: 24 de abril de 2014]

Consejo General del Podel Judicial (CGPJ), Informe sobre el Anteproyecto de Ley Orgánica de medidas de reforma para el cumplimiento integro y efectivo de las penas (4 de febrero de 2003). Disponible en <http://www.poderjudicial.es/cgpj/es/Poder_Judicial/Consejo_General_del_Poder_Judicial/ Actividad_del_CGPJ/Informes >, 2003, [fecha de visita: 24 de abril de 2014$] 50$ pp.

Corcoy Bidasolo, M., "Problemática jurídico-penal y políticocriminal de la regulación de la violencia de género y doméstica”, en Revista de Derecho, Universidad Católica de Valparaíso, XXXIV, 1, 2010, pp. 305-347.

Corn, E., "Apuntes acerca del problema de la discriminación y de su tratamiento penal", en Revista chilena de derecho y ciencias penales, vol. 2, n. 3, 2013, pp. 139-156.

Corn, E., "La revolución tímida. El tipo de femicidio introducido en Chile por la Ley 20.480 en la perspectiva del Derecho comparado", en Revista de Derecho, Universidad Católica del Norte, vol. 21, n. 2, 2014, pp. 103-136.

Corn, E., "El tipo de femicido entre violencia intrafamiliar y violencia de género. Reflexiones para un debate europeo a partir de la experiencia chilena”, en Pérez Álvarez, F., (dir.), III Congreso Internacional de Jóvenes Investigadores en Ciencias Penales (Actas), Salamanca, 17/19.06.2013, Ediciones Universidad de Salamanca, Salamanca (España), 2014 (en prensa).

Cury Urzúa, E., "El estado de necesidad en el Código Penal chileno", en AA.VV., La ciencia penal en la Universidad de Chile, Facultad de Derecho - Universidad de Chile, Santiago, 2013, pp. 250-266.

David, R., Le droit comparé: droits d'hier, droits de demain, Economica, París, 1982, 362 pp.

Díez Ripollés, J.L., La racionalidad de las leyes penales, Trotta, Madrid, 2003, 205 pp.

Etcheberry, A., Derecho penal - Parte general, III edición, Tomo II, Editorial Jurídica, Santiago, 1998, 269 pp.

FernÁndez Cruz, J.A., "El juicio constitucional de proporcionalidad de las leyes penales: ¿la legitimación democrática como medio para mitigar su inherente irracionalidad?”, en Revista de Derecho, Universidad Católica del Norte - Coquimbo, XVII, 1, 2010, pp. 51-99. 
Ferrajoli, L., "La differenza sessuale e le garanzie dell'uguaglianza", en Democrazia e Diritto, 2, 1993, pp. 49-73.

Fornasari, G., Menghini, A., Percorsi europei di diritto penale, III edición, Cedam Padua, 2012, 268 pp.

Fornasari, G., "Conquiste e sfide della comparazione penalistica", en Dolcini, E., Paliero, C.E., (dir.), Studi in onore di Giorgio Marinucci, Giuffrè, Milán, 2006, pp. 265-282.

Fuensalida, A., Concordancias y Comentarios - Código Penal Chileno, Imprenta Comercial, Lima, 1883,337 pp.

García Albero, R., Tamarit Sumalla, J., La reforma de la ejecución penal, Tirant lo Blanch, Valencia, 2004, 155 pp.

Garita Vilchez, A.I., La regulación del delito de Femicidio/Feminicidio en América Latina y el Caribe, Campaña del Secretario General ÚNETE para poner fin a la violencia contra las mujeres, Ciudad de Panamá, 2013, 118 pp.

Goyena Huerta, J., "De la circunstancia mixta de parentesco", en Gómez Tomillo, M. (dir.), Comentarios al Código Penal, II edición, Lexnova, Valladolid, 2011, pp. 222-225.

Hernández Basualto, H., "Discriminación y Derecho Penal", en Revista chilena de derecho y ciencias penales, vol. 2, n. 3, 2013, pp. 157-175.

Hernández Basualto, H., “Artículo 10”, en Mera Figueroa, J., Couso, J., Hernández Basualto, H., y otros (dir.), Código penal comentado - Parte general, Legal Publishing, Santiago, 2011, pp. 267-275.

InsolerA, G., "Principio di eguaglianza e controllo di ragionevolezza sulle norme penali", en Insolera, G., Mazzacuva, N., Pavarini, M., Zanotti, M. (dir.), Introduzione al sistema penale, IV edición, Tomo I, Giappichelli, Torino, 2012, pp. 394-435.

Lagarde y de los Ríos, M., Los cautiverios de las mujeres. Madresposas, monjas, putas, presas y locas, IV edición, coedición CEIICH-UNAM, Ciudad de México, 2005, 883 pp.

Larrauri, E., Criminología crítica y violencia de género, Trotta, Madrid, 2007, 152 pp.

Laurenzo Copello, P., "Apuntes sobre el feminicidio", en Revista de Derecho penal y criminología -UNED, 8, 2012, pp. 119-143.

MAYER, M.E., Normas jurídicas y normas de cultura (trad. y prólogo de José Luis Guzmán Dalbora), Hammurabi, Buenos Aires, 2000, 173 pp.

Mera Figueroa, J., “Artículo 12 ( $6^{\mathrm{a}}$ y $18^{\mathrm{a}}$ )”, en Mera Figueroa, J., Couso, J., Hernández Basualto, H., y otros (dir.), Código penal comentado - Parte general, Legal Publishing, Santiago, 2011, pp. 329-331 y 353-358.

Mera Figueroa, J., "Femicidio", en Red chilena contra violencia doméstica y sexual (Dir.) Tipificación del femicidio en Chile: un debate abierto, disponible en: <http://www.boell-latinoamerica.org/downloads/Tipificar_el_femicidio_un_debate_abierto.pdf>, Santiago de Chile, 2009, [fecha de visita 24 de abril de 2014] pp. 53-57.

Mir Puig, S., Derecho penal. Parte general, VIII edición, Reppertor, Barcelona, 2008, 788 pp.

Ossandón Widow, M.M., "La faz subjetiva del tipo de parricidio", en Revista de Derecho, Universidad Católica de Valparaíso, XXXIV, 1, 2010, pp. 415-457.

PaCheco, J.F., El Código Penal Concordado y Comentado, Imprenta de Manuel Tello, Madrid, 1867, 536 pp.

Politoff, S., "Informe sobre los delitos de discriminación en el derecho penal comparado (a la luz del Proyecto de Ley sobre discriminación racial y étnica (Boletín $\mathrm{N}^{\circ}$ 2142-17))”, en Ius et Praxis, 5, No 2, 1999, pp. 193-213.

Politoff L., S., Matus A., J.P., Ramírez G., M.C., Lecciones de Derecho Penal Chileno - Parte Especial, II edición, Editorial Jurídica, Santiago, 2005, 690 pp.

Politoff, S., Grisolía F., Bustos, J., Derecho penal chileno. Parte Especial. Delitos contra el individuo en sus condiciones físicas, Editorial Jurídica, Santiago, 1992.

Pradel, J., Droit pénal comparé, III edición, Dalloz, París, 2008, 892 pp.

Puricelli, J.L., "Violencia de género. Reflexiones sociológicas y jurídicas", en Revista de Doctrina Judicial, XXIX, 42, 2013, pp. 13-25. 
Ramírez Guzmán, M.C., "Anteproyecto de Código Penal: hacia una racionalización de las circunstancias modificatorias de responsabilidad penal. El caso de las agravantes", en Política criminal, 4, A2, 2007, pp. 1-22.

Retamal Herrera, J., "Intervención para agregar una circunstancia calificante por parentesco", en VV.AA. "Materiales de discusión presentados a la Comisión Foro Penal - Parte Especial", en Politica criminal, 1, D3, 2006, pp. 10-11.

Ried S., N., "Un delito propio. Análisis de los fundamentos de la ley de femicidio", en Revista de Estudios de la Justicia, 16, 2012, pp. 171-193.

Rodríguez Collao, L., Delitos sexuales, reimpresión de la primera edición con anexo de actualización, Editorial Jurídica, Santiago, 2012, 352 pp.

RodríGuez Manríquez, R., "Informe sobre femicidio en Chile. Estadísticas relevantes 2012 y datos comparativos", en Revista jurídica del ministerio público, LIII, diciembre, 2012, pp. 165-174.

Russell, E.H., D., Caputi, J., "Femicide: Sexist terrorism against women”, en Radford, J., Russell E.H., D., (ed.), Femicide: The Politics of Woman Killing, Nueva York, NY, 1992, pp. 13-24.

SACCO, R., "Legal Formants: A Dynamic Approach to Comparative Law (Installment I of II)", en The American Journal of Comparative Law, vol. 39, n. 1 (Winter), 1991, pp. 1-34.

SACCO, R., "Legal Formants: A Dynamic Approach to Comparative Law (Installment II of II)", en The American Journal of Comparative Law, vol. 39, n. 2 (Spring), 1991, pp. 343-401.

SAlinero Echeverría, S., "La nueva agravante penal de discriminación. Los "delitos de odio", Revista de Derecho, Universidad Católica de Valparaíso, XLI, 2, 2013, pp. 263-308.

SAntibÁÑEz Torres, M.E., Vargas Pinto, T., "Reflexiones en torno a las modificaciones para sancionar el femicidio y otras reformas relacionadas (Ley 20.480)", en Revista chilena de Derecho, XXXVIII, 1, 2011, pp. 193-207.

SCheECHLer Corona, C., "El cónyuge y el conviviente en el Código Penal chileno: perspectivas de un tratamiento (dispar) desde la ley de violencia intrafamiliar", en Doctrina y Jurisprudencia Penal, 11, 2012, pp. 25-46.

Taladriz Eguiluz, M.J., Rodríguez Manríquez, R., "El delito de femicidio en Chile”, en Revista jurídica del ministerio público, XLVI, marzo, 2011, pp. 213-229.

TAPIA Ballesteros, P., "Legítima defensa. Requisitos y aplicabilidad en supuestos de violencia de género", en Doctrina y Jurisprudencia Penal, 16, 2014, pp. 37-60.

Toledo Vásquez, P., "Leyes sobre femicidio y violencia contra las mujeres. Análisis comparado y problemáticas pendientes”, en Red chilena contra violencia doméstica y sexual (Dir.) Tipificación del femicidio en Chile: un debate abierto, disponible en: <http://www.boell-latinoamerica.org/downloads/Tipificar_el_femicidio_un_debate_abierto.pdf, Santiago de Chile, 2009, [fecha de visita 24 de abril de 2014] pp. 41-50.

Toledo Vásquez, P., “'Tipificar el femicidio?”, en Anuario Der. Humanos U.Ch., 4, 2008, pp. 213-219.

VALDÉs Echenique, T., "La CEDAW y el Estado de Chile: viejas y nuevas deudas con la igualdad de género", en Anuario Der. Humanos U.Ch., 9, 2013, pp. 171-181.

VAN Weezel de la Cruz, A., "Lesiones y violencia intrafamiliar", en Revista chilena de Derecho, XXXV, 2, 2008, pp. 223-259.

Villegas Díaz, M., "Homicidio de la pareja en violencia intrafamiliar. Mujeres homicidas y exención de la responsabilidad penal", en Revista de Derecho, Universidad Austral de Chile, XXXIII, 2, 2010, pp. 149-174.

Zaffaroni, E.R., Alagia, A., Slokar, A., Derecho penal - parte general, II edición, Ediar, Buenos Aires, 2006, 790 pp.

Zaffaroni, E.R., "Observaciones sobre la delincuencia por odio en el Derecho Penal argentino", en García Valdés, C., et alii (Eds.), Estudios Penales en homenaje a Enrique Gimbernat, Tomo II, Edisofer, Madrid, 2008, pp. 1735-1748. 